\title{
Study of Variation of Internal Taget Volume between 4DCT and Slow-CT in Respiratory Patterns Using Respiratory Motion Phantom
}

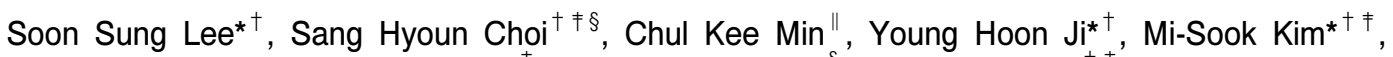 \\ Hyoung Jun $\mathrm{Yoo}^{\dagger}$, Chan Hyeong $\mathrm{Kim}^{\S}$, Kum Bae Kim* ${ }^{{ }^{\dagger}}$ \\ *Radiological Cancer Medicine, University of Science and Technology, Daejeon, \\ ${ }^{\dagger}$ Research Center for Radiotherapy, Korea Institute of Radiological and Medical Sciences, \\ ${ }^{\ddagger}$ Department of Radiation Oncology, Korea Institute of Radiological and Medical Sciences, \\ ${ }^{\S}$ Departement of Nuclear Engineering, Hanyang University, Seoul, \\ "SoonChunHyang University Cheonan Hospital, Department of Radiation Oncology, Cheonan, Korea
}

\begin{abstract}
The objective of this study is to investigate the difference of ITV lengths and ITVs between 4DCT and Slow-CT images according to respiratory patterns using a respiratory motion phantom. The respiratory periods $1 \sim 4 \mathrm{~s}$ and target motion $1 \sim 3 \mathrm{~cm}$ were applied on each respiratory pattern. $4 \mathrm{DCT}$ and Slow-CT images were acquired for 3 times. 4DCT and Slow-CT ITVs were measured with contouring the target in the Eclipse RTP system. The measured ITV lenghts and ITVs in 4DCT and Slow-CT images were compared to the known values. For the ITV lengths and ITVs in the 4DCT, the difference of them were reduced as the respiratory period is longer and target motion is shorter. For the Slow-CT, there was same tendency with change in 4DCT ITV lengths and ITVs about target motion. However, the difference of ITV lengths and ITVs for the respiratory periods were the lowest in respiratory period 1 second and different slightly within respiratory period 2-4 seconds. According to the respiratory patterns, pattern $A$ had the highest reproducibility. Pattern $B, C$ and $D$ were showed the difference similar to each other. However, for pattern $\mathrm{E}$, the reproducibility was the lowest compared with other four patterns. The difference of ITV lengths and ITVs between Slow-CT and 4DCT was increased by increasing the respiratory periods and target motion for all respiratory patterns. When the difference of Slow-CT ITV lengths and ITVs were compared with that of 4DCT ITV lengths and ITVs, Slow-CT ITV lengths and ITVs were approximately $22 \%$ smaller than $4 \mathrm{DCT}$, and the representations of target were different in each pattern. In case of pattern $\mathrm{A}, \mathrm{B}$ and $\mathrm{C}$, length difference was $3 \mathrm{~mm}$ at $\mathrm{S}$ (superior) and I (inferior) direction, and the length difference of pattern D was $1.45 \mathrm{~cm}$ at only "l" direction whereas the length difference of pattern $\mathrm{E}$ was $5 \mathrm{~mm}$ longer in "S" direction than "I" direction. Therefore, the margin in SI directions should be determined by considering the respiratory patterns when the margin of Slow-CT is compensated for 4DCT ITV lengths. Afterward, we think that the result of this study will be useful to analyze the ITV lengths and ITVs from the CT images on the basis of the patient respiratory signals.
\end{abstract}

Key Words: 4DCT, Slow-CT, Respiratory patterns, Respiratory motion phantom, ITV

This project was supported by Ministry of Sciencr, ICT and Future Planning.

Received 5 March 2014, Accepted 16 March 2014 Correspondence: Kum Bae Kim (kbkim@kirams.re.kr) Tel: 82-2-970-2475, Fax: 82-2-970-2412

(C) This is an Open-Access article distributed under the terms of the Creative Commons Attribution Non-Commercial License (http://creativecommons.org/licenses/by-nc/3.0) which permits unrestricted non-commercial use, distribution, and reproduction in any medium, provided the original work is properly cited.

\section{서 론}

최근 종양에 단 기간 고선량을 조사하여 치료 효과를 높 이는 소분할방사선치료(Hypofractionated Radiotherapy)인 정 위방사선수술(Stereotactic Radiosurgery, SRS)과 정위신체방 사선치료(Stereotactic Body Radiotherapy, SBRT)에 대한 관 심이 높아짐에 따라 노발리스, 사이버나이프, 감마나이프 등의 최신 방사선 치료 기기들을 이용한 고정밀, 고정확한 치료가 이루어지고 있다. ${ }^{1-3)}$ 이 치료들은 한 번에 고선량을 
조사하기 때문에 정상 조직이 치료 범위에 포함되면 한계 선량 이상을 조사할 수 없으므로 처방선량대로 치료를 할 수 없게 된다. 따라서 SRS나 SBRT 같은 소분할방사선치료 의 효율을 최대한 높이기 위해서는 표적 체적이 정확하게 정의되어야 하며, 특히 움직이는 장기 내에 위치한 종양의 경우에는 내부표적체적을 정확히 정의해야 한다.

미국의학물리학회의 Task Group 76 보고서(AAPM TG-76 Report)는 종양의 움직임 범위를 알 수 있는 영상 획득 방 법으로 크게 3 가지를 권고한다. ${ }^{4)}$ 첫 번째로 $4 \mathrm{DCT}$ 는 RPM 호흡 동조 시스템(Varian Medical Systems, Palo Alto, CA)을 통하여 획득한 호흡신호를 기반으로 CT 영상을 획득하고 호흡신호의 위상별로 영상을 재구성하는 촬영 기법이다. 호흡 위상마다 종양의 위치를 확인할 수 있어 최근까지 소 개된 다른 CT 영상 방법에 비해 종양 움직임의 범위를 정 확하게 정의할 수 있다는 장점이 있다. 하지만 긴 촬영 시 간으로 인해 호흡의 변동에 따라 영상이 변하고 피폭 선량 이 많은 단점이 있어서 모든 환자에 적용하기에는 한계가 있다. ${ }^{5)}$ 두 번째로 호흡정지 기법(breath-hold technique)은 최 대 흡기(End-Inspiration)와 최대 호기(End-Expiration)에서 호 흡을 일정 시간동안 유지시켜 촬영하는 기법이다. 최대 흡 기와 최대 호기의 영상에 나타난 표적간의 거리로 표적 진 폭의 범위를 확인 할 수 있어 $4 \mathrm{DCT}$ 에 비해 피폭 선량이 적고, 호흡패턴에 따른 변화가 작다는 장점이 있다. 하지만 일반 CT 영상에 비해 2 배 이상의 촬영 시간이 소요되며 최 대 호기와 흡기에서 호흡을 유지하여 촬영이 이루어지기 때문에 환자에 따라 재현성이 달라 질 수 있다. 즉, 깊은 호흡 상태에서 호흡을 유지하여 촬영하게 되면 종양의 움 직임 범위가 커져서 자유호흡(Free-breathing) 상태에서 치 료 시, 실제 치료 범위에 비해 과하게 치료될 수 있으며, 종양의 실제 움직임 범위보다 얕은 호흡 상태에서 호흡을 유지하게 되면 치료가 제대로 시행되지 않을 수 있다. 마지 막으로 Slow-CT는 긴 주사시간(scan time)을 이용하여 표적 이 운동하는 동안 천천히 촬영하는 기법으로 $4 \mathrm{DCT}$ 와 달리 대부분의 $\mathrm{CT}$ 촬영기기를 이용하여 촬영 할 수 있다. 또한 자유호흡 상태에서 1 회 촬영이 이루어지기 때문에 환자의 부담이 적다는 장점이 있다. 하지만 다른 두 촬영 기법에 비해 표적의 움직임에 영향을 많이 받아 심각한 허상이 나 타나 표적을 정확하게 표현할 수 없다. 이는 $4 \mathrm{DCT}$ 와 호흡 정지 기법에 비해 더 많은 움직임에 대한 보상을 통해 해 결 할 수 있지만 호흡패턴, 호흡주기, 호흡 진폭 등의 환자 의 상태에 따라 달라 질 수 있으므로 명확히 표적의 움직 임 범위를 정의하기가 어렵다.
이러한 이유로 많은 연구자들은 방사선 치료 목적으로 촬영된 영상 기법에 따라 표적 움직임의 범위와 내부표적 체적의 차이에 대해 연구 해왔다. Lagerwaard 등은 10 명의 환자를 주사시간 1 초, 4 초의 Slow-CT를 촬영한 결과 주사 시간 4초로 촬영하여 재구성한 Slow-CT 영상이 주사시간 1 초에 비해 종양 체적이 약 $13 \%$ 가 크다고 보고하였다.) 또 한 $\operatorname{Kim}$ 등의 연구에서는 $2 \mathrm{~cm}$ 왕복 운동하는 팬톰을 호흡 주기에 대한 상대주사시간을 증가 시키며 Slow-CT를 촬영 한 결과 주사시간이 호흡주기보다 짧을 때에 비해 호흡주 기와 같거나 그 이상의 주사시간으로 촬영하는 것이 표적 을 잘 나타내었다고 보고하였다. ${ }^{7)}$

위 연구와 같이 Slow-CT는 환자 호흡주기에 따라 충분히 긴 주사시간으로 촬영 했을 때 표적의 범위를 더 잘 표현 하였다. 하지만 Nakamura 등의 연구에 따르면 표적 진폭이 $8 \mathrm{~mm}$ 이하인 32 명의 폐종양 환자에 대하여 최대 호흡주기 보다 긴 주사시간으로 Slow-CT를 촬영하여도 Slow-CT에서 표현되는 종양의 체적이 $4 \mathrm{DCT}$ 에서 보다 평균 $8 \%$ 작다고 보고하였다. ${ }^{8)}$ 게다가 환자의 호흡패턴, 호흡주기 및 표적 진폭이 달라지면 Slow-CT에서 표현되는 종양의 체적이 $4 \mathrm{DCT}$ 와 비교하였을 때 더 큰 차이를 보일 수 있지만 아직 까지 이런 연구가 보고 되지 않았다. 따라서 본 연구에서는 환자의 호흡패턴및 호흡주기, 표적 진폭에 따른 Slow-CT의 영상 차이를 $4 \mathrm{DCT}$ 와 비교하여 분석하였다.

\section{재료 및 방법}

\section{1. 환자 호흡패턴 분석}

본 연구에서는 본원과 타 병원에 내원한 238명 환자들의 호흡 신호를 Varian사의 RPM 호흡 동조 시스템을 이용하 여 획득하였다. RPM 파일의 호흡 신호를 그대로 모사할 수 있는 Modus사의 호흡 동조 모션 프로그램(Modus Medical devices)에 환자들의 RPM 파일을 적용하여 호흡 신호의 패턴을 분석하였다.

\section{2. 호흡 동조 구동 팬톰}

본 연구에서 다양한 호흡패턴에 따른 표적의 움직임을 모사하기 위해서 $\mathrm{QUASAR}^{\mathrm{TM}}$ 호흡 동조 구동 팬톰(Modus Medical Devices Inc., London, ON, Canada)을 사용하였다. $\mathrm{QUASAR}^{\mathrm{TM}}$ 팬톰은 아크릴 재질의 타원형 팬톰 및 구동 모 터, 지름 $3 \mathrm{~cm}$ 의 표적이 삽입되어 있는 원통형 삽입물로 구성되며 호흡패턴에 따라 표적 움직임을 모사 할 수 있다. $\mathrm{QUASAR}^{\mathrm{TM}}$ 팬톰과 함께 제공되는 호흡 동조 모션 프로그 

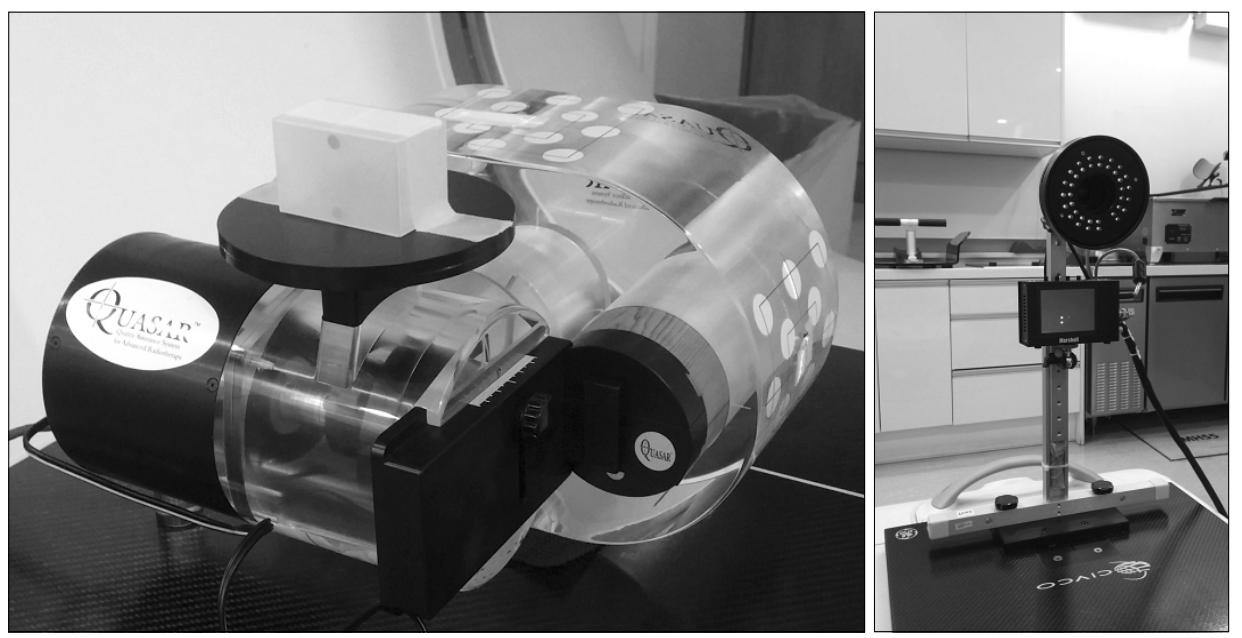

Fig. 1. QUASAR ${ }^{\mathrm{TM}}$ Programmable Respiratory Motion Phantom (left) and RPM Respiratory Gating system (right).

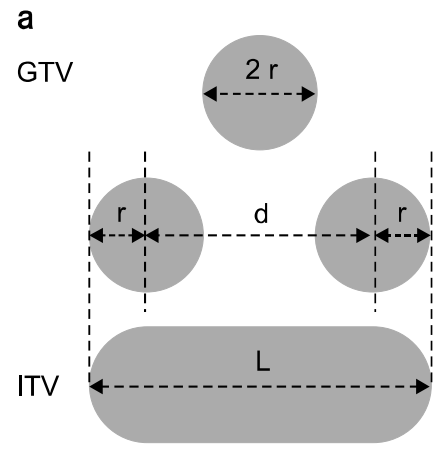

ITV length b

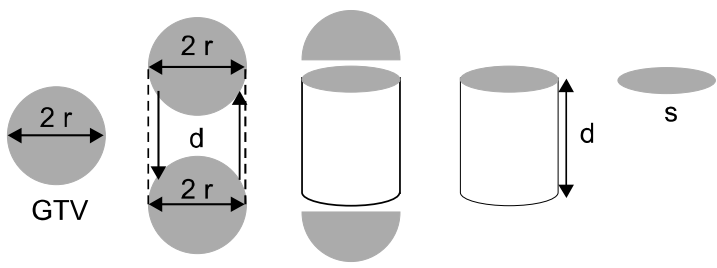

ITV

Fig. 2. Definition of ITV length and ITV.
램을 이용하여 원하는 호흡패턴, 표적 진폭, 호흡주기를 조 절 및 제작이 가능하며 최대 $3 \mathrm{~cm}$ 의 표적 진폭과 $1 \sim 15$ 초 의 호흡주기를 적용할 수 있다(Fig. 1). 본 연구에서는 호흡 동조 모션 프로그램을 이용하여 호흡패턴을 제작하였으며 $1,2,3,4$ 초의 호흡주기 및 상, 하 방향에 대한 진폭의 크기 를 $1,2,3 \mathrm{~cm}$ 로 적용하여 $\mathrm{CT}$ 를 촬영하였다.

\section{3. $4 \mathrm{DCT}$ 와 Slow-CT 영상 획득}

본 연구에서는 Lightspeed 16-Slice CT (GE Medical Systems, Milwaukee, WI)를 이용하여 4DCT와 Slow-CT 영상을 획득하였으며 두 촬영법 모두 호흡패턴, 호흡주기, 표적 진 폭에 따라 3회씩 반복 촬영하였다. 4DCT 영상은 RPM 호 흡 동조 시스템을 이용하여 호흡신호를 획득한 후, 이를 기 반으로 Advantage 4D software v1.4 (GE, WC, USA)를 이용 하여 $0 \%$ 부터 $90 \%$ 까지 10 개의 위상으로 나누어 영상을 재 구성 하였다(Fig. 1). 4DCT 촬영은 연속적 주사방법(cine mode)을 사용하였으며 연속 간격(cine interval)을 호흡주기
의 $1 / 10$, 지속 시간은 호흡주기에 회전 시간 1 초를 합산하 여 설정하였다.

Slow-CT 촬영은 일반적 주사방법인 횡단면 주사방법 (axial mode)을 사용하였다. 주사시간은 호흡주기와 같거나 길게 설정할 경우 표적의 재현성이 비슷하기 때문에 호흡 주기와 동일하게 설정하였다. ${ }^{7}$ 관전압과 관전류, 절편 두께 는 4DCT와 Slow-CT 모두 $140 \mathrm{kVp}, 55 \mathrm{~mA}, 2.5 \mathrm{~mm}$ 로 적용 하였다. 내부표적체적(ITV) 길이와 체적은 Eclipse 치료계 획 시스템(Varian Medical Systems, Palo, CA, USA)을 이용 하여 영상에 나타난 표적을 각 절편마다 윤곽 묘사하여 측 정하였다. $4 \mathrm{DCT}$ 의 경우는 최대세기투영법(MIP) 영상을 생 성하여 윤곽 묘사하였다. 표적의 윤곽은 윈도우 레벨 및 폭 (window level/width)에 따라 표적의 표현 정도가 매우 상이 하므로 일정한 윈도우 레벨 및 폭을 지정하기 위해서 움직 이지 않는 표적을 4DCT와 Slow-CT 촬영하여 표적의 지름 이 $3 \mathrm{~cm}$ 가 되는 값으로 설정하였으며 모든 영상에 대하여 동일하게 적용하였다. 이때 윈도우 레벨 및 폭은 180/-500 
이였다.

\section{4. 내부표적체적의 이론적 계산}

ITV 길이의 이론값에 대한 계산은 반지름이 $r$ 인 표적의 중심을 기준으로 $d$ 만큼 이동하였을 때, 최대호기와 최대흡 기에서 표적의 지름을 합산한 길이 $(L)$ 를 이론값으로 정의 하였다(Fig. 2a). ITV 체적은 최대호기와 최대흡기 위치에 $2 r$ 의 지름을 가지는 표적이 위치한다고 가정했을 때, 표적 과 같은 지름을 갖고 이동거리 $(d)$ 의 높이를 가지는 원통의 부피와 표적의 부피를 합산한 부피 $(V)$ 를 이론값으로 하였 다(Fig. 2b). 각 이론값에 대한 관계식은 다음과 같다.

$L=2 r+d$

$V=\frac{4}{3} \pi r^{3}+\left(\pi r^{2} \times d\right)$

Table 1. Theoretical value of ITV length and ITV.

\begin{tabular}{lccc}
\hline \hline & \multicolumn{3}{c}{ Target motion $(\mathrm{cm})$} \\
\cline { 2 - 4 } & 1 & 2 & 3 \\
\hline Known ITV length $(\mathrm{cm})$ & 4 & 5 & 6 \\
Known ITV $\left(\mathrm{cm}^{3}\right)$ & 21.21 & 28.28 & 35.35 \\
\hline \hline
\end{tabular}

여기서 $L$ 은 ITV 길이이고, $V$ 는 ITV 체적을 의미한다. ITV 의 관계식(2)에서 $\frac{4}{3} \pi r^{3}$ 은 맨눈표적체적(GTV)을 나타내며 $\pi r^{2} \times d$ 는 표적의 지름 $(2 r)$ 과 같고 표적의 이동거리 $(d)$ 와 같 은 높이를 갖는 원통의 부피를 나타낸다. 식 (1)과 (2)에 3 $\mathrm{cm}$ 의 표적지름 $(2 r)$ 과 표적 진폭을 대입하여 Table 1 과 같은 이론값을 구하였다.

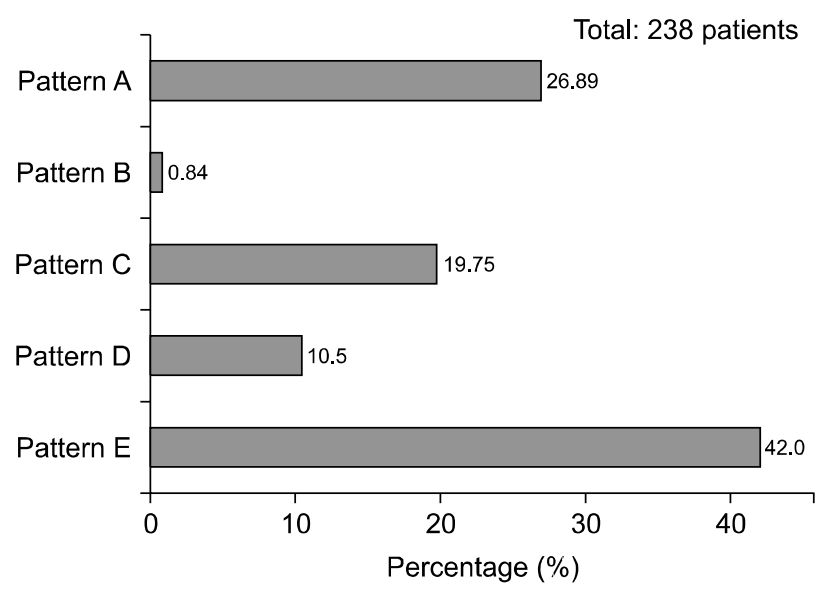

Fig. 3. Distribution of patient respiratory patterns.

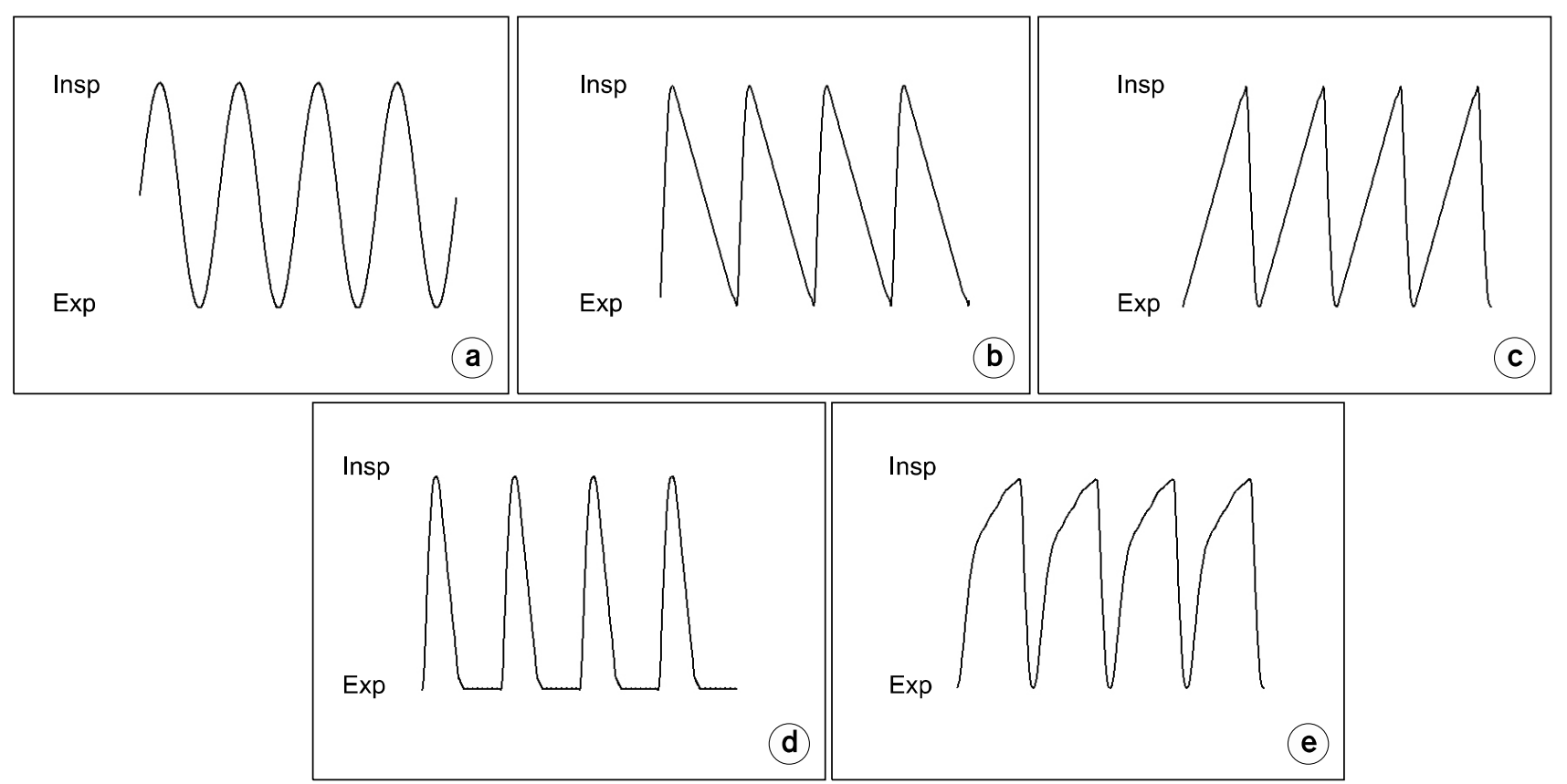

Fig. 4. Computed respiratory patterns. (a) sinusoidal pattern, (b) inspiration shorter than expiration, (c) inspiration longer than expiration, (d) inspiration shorter than expiration followed by rest period, (e) inhaling gradually after inhaling rapidly. The "Insp" means for inspiration and the "Exp" means for expiration. 


\section{결 과}

\section{1. 환자 호흡 신호 분석}

본원과 타 병원에 내원한 환자들의 호흡 신호 데이터를 분석하여 총 5 가지 호흡패턴으로 분류한 결과, $\mathrm{E}$ 패턴의 호 흡 특성을 지닌 환자가 $42.02 \%$ (100명)로 가장 많았으며 A 패턴의 경우에는 $26.89 \%$ (64명), C패턴은 $19.75 \%$ (47명), D 패턴은 $10.5 \%$ ( 25 명), B패턴의 경우에는 $0.84 \%$ (2명)로 가 장 적었다(Fig. 3). 각 호흡패턴에 대한 특성은 호기와 흡기 의 주기가 같은 사인형 패턴(Pattern $\mathrm{A})$, 호기가 흡기보다 긴 패턴(Pattern B), 호기가 흡기보다 짧은 패턴(Pattern C), 최대 호기에서 호흡이 유지되는 패턴(Pattern D) 그리고 처 음 흡기에서 숨을 급격하게 흡입하다가 중간에 완만하게 흡입하는 패턴(Pattern E)이다. 분류한 5가지의 호흡패턴 중 에 A-D패턴은 Clements 등의 연구에서 제시된 호흡패턴을 바탕으로 분류하였으며 ${ }^{9)} \mathrm{E}$ 패턴은 가장 많은 환자들이 가 지는 호흡패턴이기 때문에 추가 분류하였다. 분류된 호흡 패턴에 대한 호흡 신호는 호흡 동조 모션 프로그램으로 제 작하였다(Fig. 4).

\section{2. $4 \mathrm{DCT} / \mathrm{Slow}-\mathrm{CT}$ 와 이론값의 ITV 비교}

4DCT와 Slow-CT에서 측정한 ITV 길이와 체적은 모두 식(1), (2)으로 구한 이론값보다 적게 나타났다. 먼저, 4DCT 의 호흡주기에 따른 ITV 길이의 변화는 Fig. 5 에서 보는 바 와 같이 호흡패턴이 $\mathrm{A}$, 진폭이 $1 \mathrm{~cm}$ 일 때 이론값과 차이 가 가장 적었으며 $1,2,3,4$ 초의 경우 각각 $10,7,7,2 \%$ 의 차이를 보였다. B, C, D 패턴들은 호흡주기 및 표적 진폭 에 따른 각 패턴간의 ITV 길이의 차이가 크지 않았으며 특 히, $\mathrm{E}$ 패턴은 모든 경우에서 다른 패턴들에 비해 더 많은 차이를 보였다. ITV 길이는 대체로 호흡주기가 길어질수록 진폭이 작을수록 이론값에 가까운 값을 보였으나 호흡주기 가 3,4 초의 경우 ITV 길이의 차이는 각각 $3 \%, 2 \%$ 로 영향 이 적음을 확인하였다.

ITV 체적의 경우 또한 A 패턴이 다른 패턴들에 비해 이 론값을 가장 잘 재현하였다. 호흡주기가 1 초의 경우 $1,2,3$ $\mathrm{cm}$ 의 표적 진폭에 따라 $10,16,18 \%$ 의 차이를 보였지만 3 초와 4 초의 경우 표적 진폭에 따른 이론값과의 차이는 $4 \%$ 이내 이었다. 특히, 호흡주기가 긴 4초에 경우 모든 표적 진폭에서 $95 \%$ 이상의 재현성을 보였다. B, C, D 패턴간의 호흡주기 및 표적 진폭에 따른 ITV 체적의 차이는 크지 않 았으며 호흡주기가 3,4 초 일 때 이론값에 대한 ITV 길이
재현성은 $85 \%$ 이상인 반면에 ITV 체적은 모든 호흡패턴이 $90 \%$ 이상의 재현성을 갖았다. $\mathrm{E}$ 패턴은 모든 경우에 다른 네 패턴에 비해 재현성이 가장 낮았고 호흡주기 3,4 초에서 는 표적 진폭이 $1 \mathrm{~cm}$ 인 경우를 제외한 모든 경우에 $90 \%$ 이하의 재현성을 보였다. 호흡주기 1 초, 표적 진폭이 $3 \mathrm{~cm}$ 일 때 $65.94 \%$ 의 재현성으로 이론값과의 차이가 가장 컸으 며 다른 호흡패턴에 비해 낮은 재현성을 보였다(Fig. 5).

Slow-CT도 4DCT와 마찬가지로 모든 호흡패턴에 대하여 표적 진폭이 짧을수록 ITV 길이 및 체적과 이론값의 차이 가 작아졌지만 호흡주기의 경우에는 1 초에서 재현성이 가 장 좋았으며 2 4초간의 차이는 매우 근소했다(Fig. 6). 호 흡패턴의 경우 A패턴이 ITV 길이와 체적 모두 다른 패턴 에 비해 이론값과의 차이가 가장 작았으며 호흡주기 1초, 표적 진폭 $1 \mathrm{~cm}$ 일 때 ITV 길이와 체적이 각각 89.50 , $80.61 \%$ 로 가장 재현성이 좋았다. E패턴은 $4 \mathrm{DCT}$ 와 Slow-CT 에서 모든 패턴에 비해 재현성이 가장 떨어졌으며 Slow-CT 에서는 호흡주기가 1 초, 진폭이 $1 \mathrm{~cm}$ 일 때 ITV 길이와 체 적이 이론값과 비교하여 각각 $79.50,71.81 \%$ 로 가장 좋은 재현성을 보였다. B, C, D 패턴은 $4 \mathrm{DCT}$ 와 마찬가지로 각 패턴간의 ITV 길이와 체적에 대한 재현성은 호흡주기와 표 적 진폭에 따라 차이가 크지 않았다.

\section{4DCT와 Slow-CT 영상 간 ITV 비교}

4DCT에 대한 Slow-CT의 ITV 길이와 체적의 차이는 모 든 패턴에 대하여 호흡주기가 길어질수록, 진폭이 커질수 록 증가함을 확인하였다(Table 2). ITV 길이와 체적의 차이 는 호흡주기가 1 초이고, 진폭이 $1 \mathrm{~cm}$ 인 경우 각각 $1 \%, 6 \%$ 이내 이었으며, 호흡주기가 4 초이고 진폭이 $3 \mathrm{~cm}$ 일 때 각 각 $15 \%, 30 \%$ 이상의 차이를 보였다. 패턴별에 따른 차이는 진폭 및 호흡주기에 따라 다르게 나타났다. $1 \mathrm{~cm}$ 의 진폭에 서는 $\mathrm{E}$ 패턴이 다른 패턴에 비해 대체로 차이가 낮았고, 진 폭이 $2 \mathrm{~cm}$ 일 때는 D패턴이 가장 많은 차이를 보인 반면에 다른 네 패턴은 ITV 길이와 체적에 대한 차이가 서로 비슷 했다. 표적 진폭이 $3 \mathrm{~cm}$ 인 경우에는 $\mathrm{A}$ 패턴이 차이가 가장 낮았으며 다른 네 패턴은 차이가 서로 비슷했다. 하지만 호 흡주기와 표적 진폭에 따라 4DCT, Slow-CT 영상에서의 호 흡패턴별 ITV 길이와 체적이 서로 상이하여 뚜렷한 경향성 을 찾을 수 없었다.

\section{고 찰}

본 연구에서는 환자의 호흡 신호를 분석하여 5 가지의 호 
Soon Sung Lee, et al : Study of Variation of Internal Target Volume between 4DCT and Slow-CT in Respiratory Patterns Using Respiratory Motion Phantom
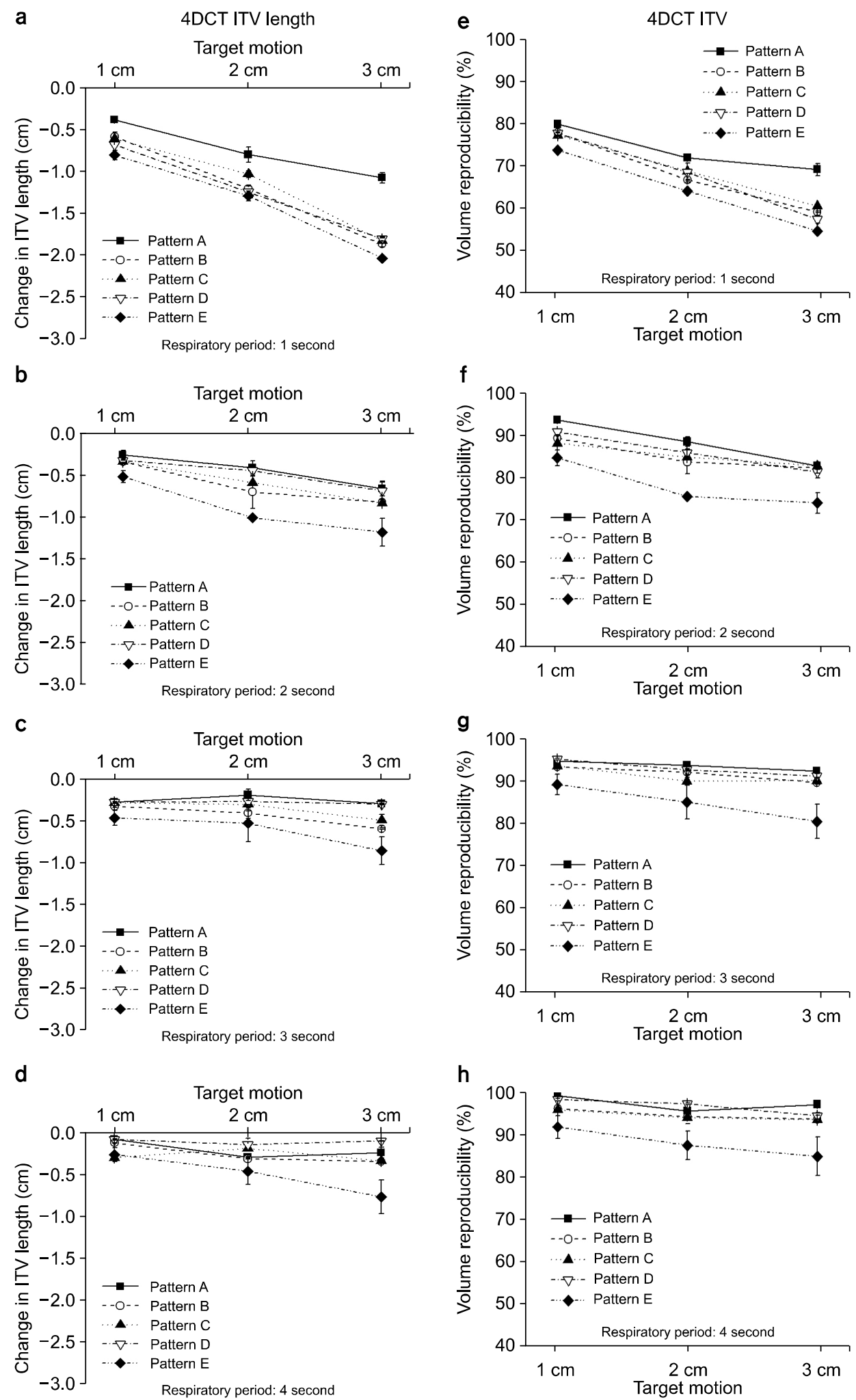

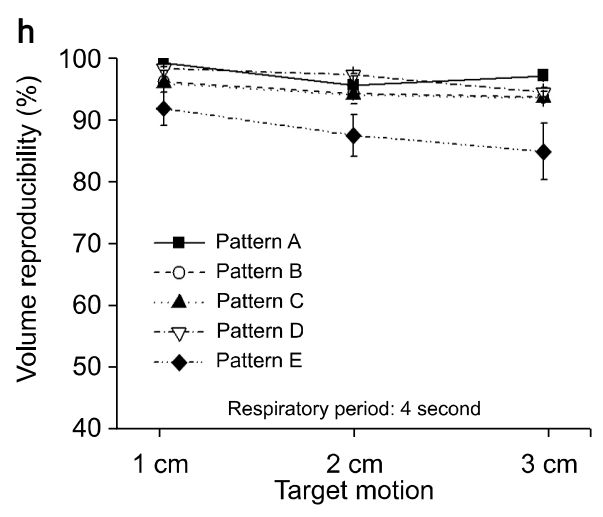

Fig. 5. Plot (a)-(d) illustrate the change in ITV length for 4DCT, and plot (e)-(h) illustrate the change in ITV for 4DCT. In (a)-(d) table, the horizontal line at $0 \mathrm{~mm}$ and $100 \%$ represent no change from known ITV length and ITV. 
a

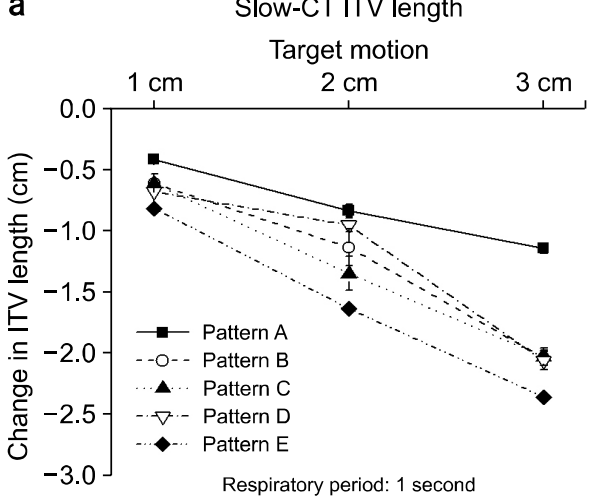

b

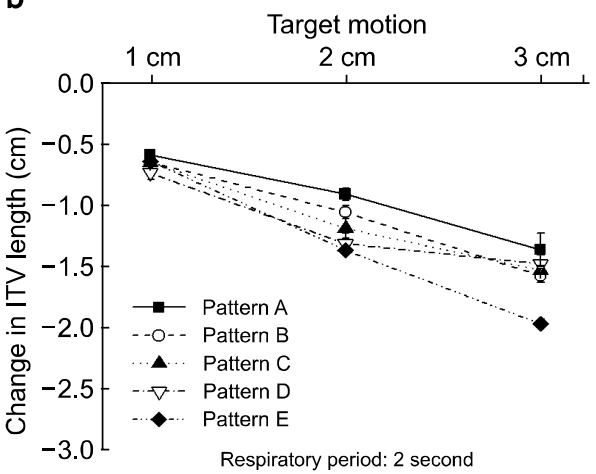

C

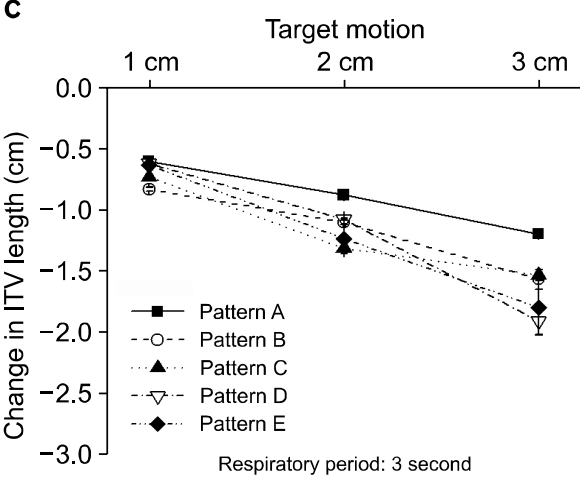

d

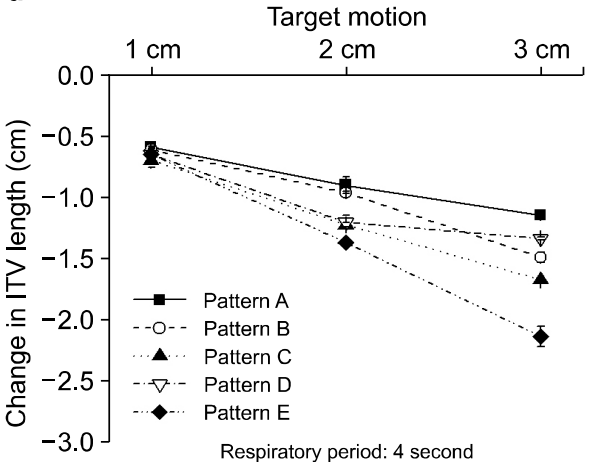

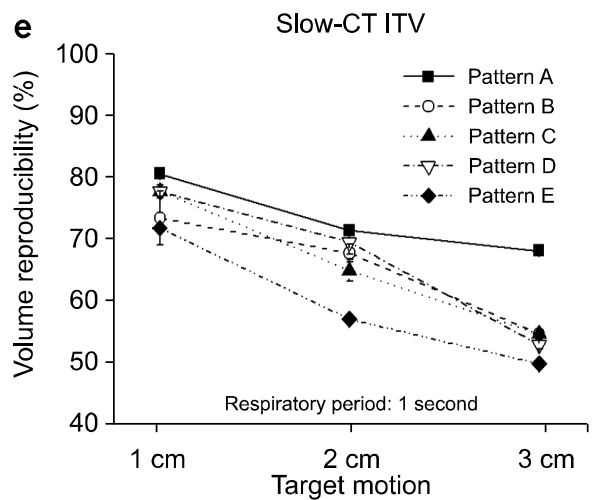
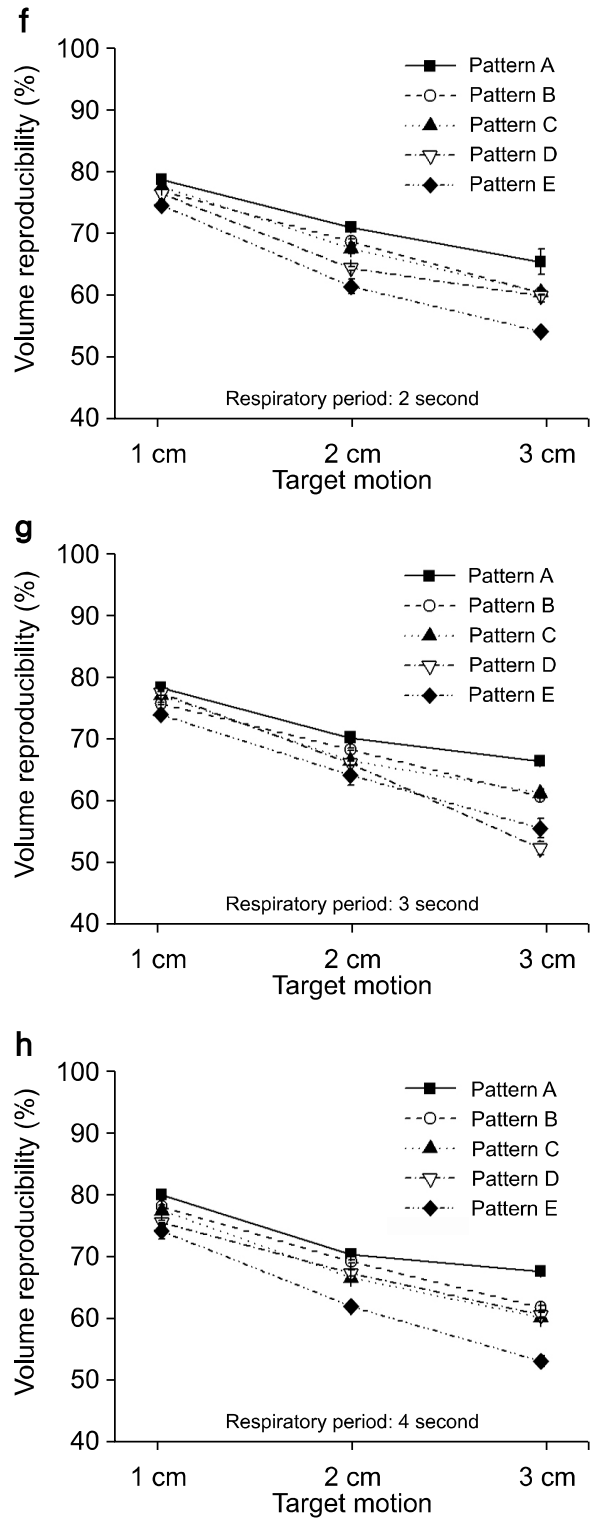

Fig. 6. Plot (a)-(d) illustrate the change in ITV length for Slow$\mathrm{CT}$, and plot (e)-(h) illustrate the change in ITV for Slow-CT. In (a)-(d) table, the horizontal line at $0 \mathrm{~mm}$ and $100 \%$ represent no change from known ITV length and ITV. 


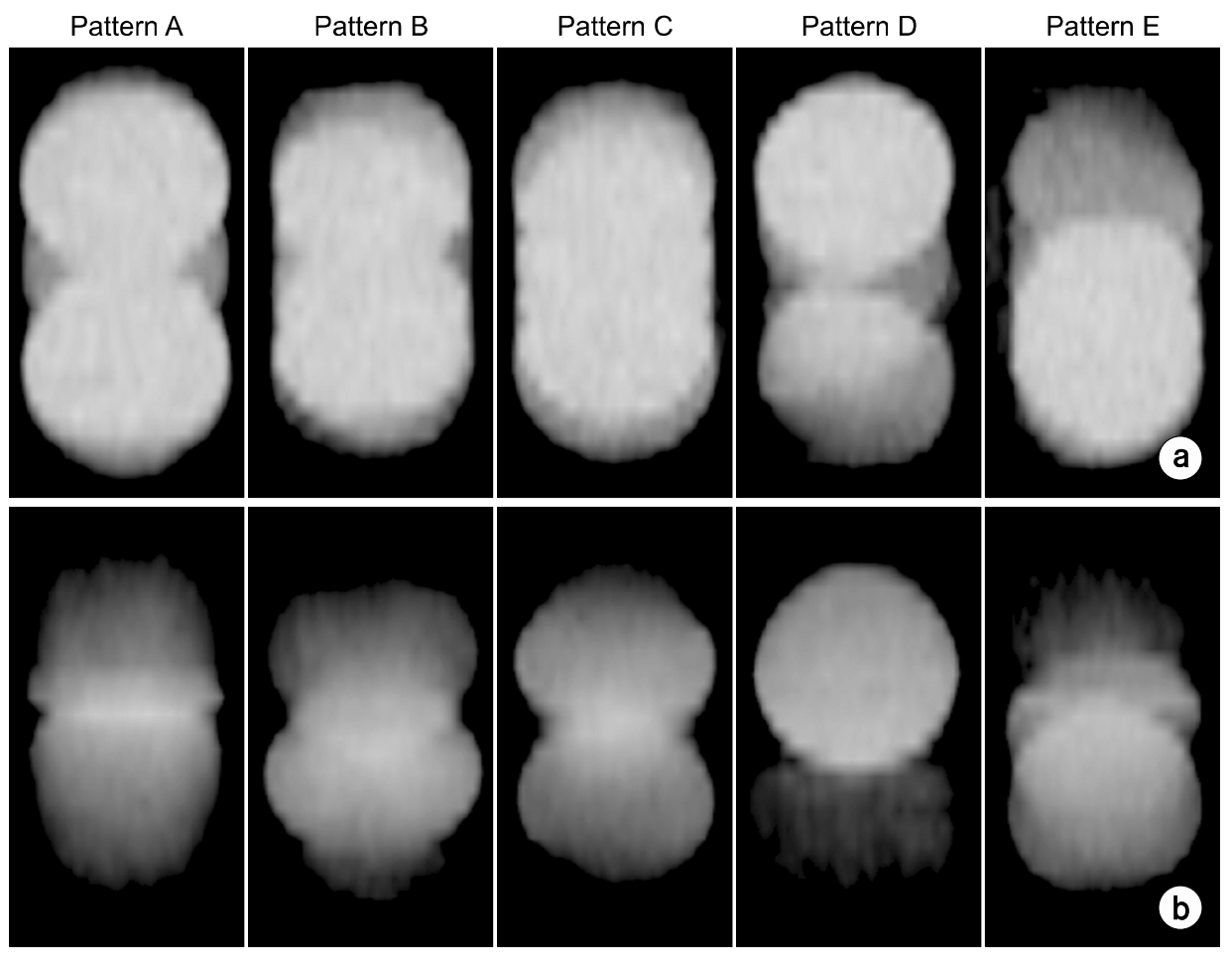

Fig. 7. Plot (a) shows 4DCT images according to respiratory patterns at respiratory period 3 seconds and target motion $3 \mathrm{~cm}$. Plot (b) shows Slow-CT images according to respiratory patterns at respiratory period 3 seconds and target motion $3 \mathrm{~cm}$, respectively.

흡패턴으로 분류하고, 이 호흡패턴들을 이용하여 호흡주기 및 표적 진폭에 따른 Slow-CT 영상에서의 ITV 길이와 체 적을 $4 \mathrm{DCT}$ 와 비교하였다. $4 \mathrm{DCT}$ 와 Slow-CT의 ITV 길이 및 체적을 이론값과 비교하였을 때, Slow-CT보다 4DCT의 재 현성이 평균적으로 약 $22 \%( \pm 0.82)$ 높게 나타났다. $4 \mathrm{DCT}$ 와 Slow-CT는 모두 같은 호흡주기에서 진폭이 작아질수록 ITV 길이와 체적 모두 재현성이 향상되는 경향을 보였는 데, 이는 동일한 호흡 진폭에서 호흡주기가 길어짐에 따라 표적의 이동속도가 감소하기 때문이며, 동일한 표적 진폭 에서 호흡주기가 길어짐에 따라 4DCT에서 ITV 길이와 체 적이 이론값에 근접한 값을 보이는 것도 또한 같은 이유에 서이다. 그러나 Slow-CT의 경우 4DCT와는 달리 동일한 표 적 진폭에서 호흡 주기의 변화는 재현성에 영향을 주지 않 았는데, 이를 통해 Slow-CT 촬영 시 주사시간을 호흡주기 에 동일하게 설정하면, 호흡주기에 상관없이 ITV 길이와 체적이 비슷한 값을 갖게 됨을 확인하였다.

패턴별로 호흡주기와 진폭에 따라 이론값과 차이가 서로 상이함 또한 표적의 이동 속도와 관련이 있다. D패턴의 경 우 최대 호기 위치에 표적이 완벽하게 묘사된 반면에 흡기 의 위치에서는 4DCT와 Slow-CT 모두 A패턴에 비해 잘 나 타나지 않았다. Clements 등의 연구도 $\mathrm{D}$ 패턴과 같은 호흡 패턴의 경우 $4 \mathrm{DCT}, \mathrm{CBCT}$ (cone-beam CT) 영상에서 흐림
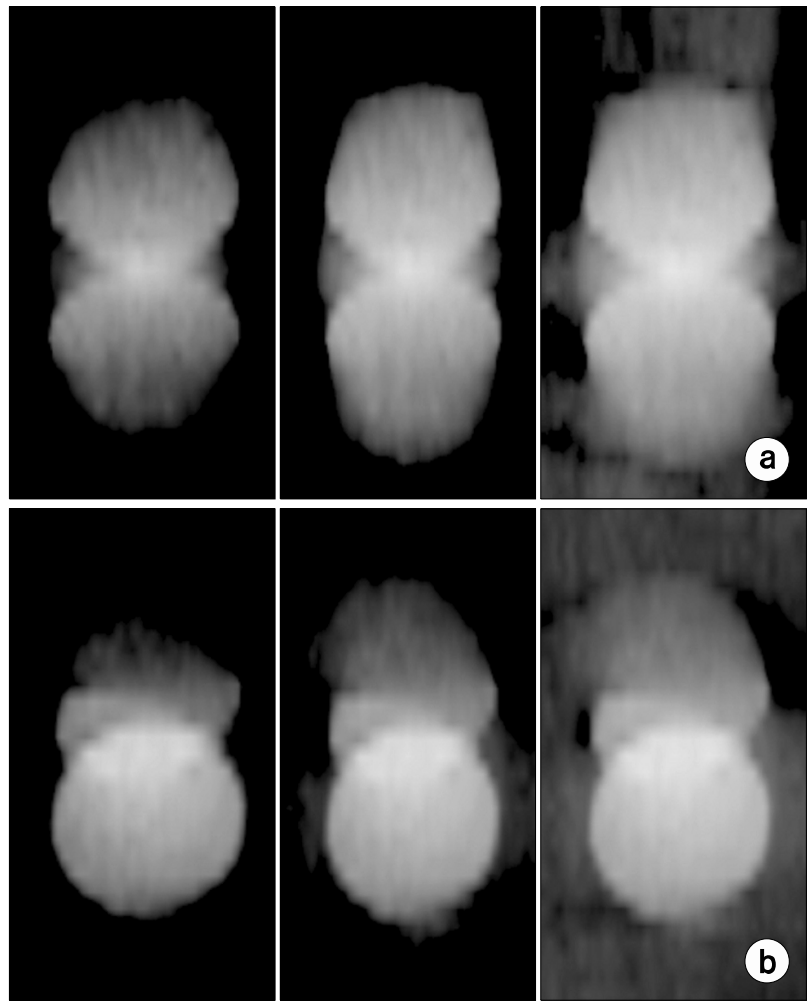

Fig. 8. The window level are $-500,-600,-700$ from left, respectively. Plot (a), (b) are images of pattern $\mathrm{A}$ and $\mathrm{E}$ at target motion $3 \mathrm{~cm}$, respiratory period 3 seconds. 
허상이 나타나 본 연구와 같은 결과를 보였으며,9) 이는 표 적이 최대 호기에서 머무는 시간에 비해 최대 흡기 위치에 머무는 시간이 상대적으로 매우 짧기 때문이다. E패턴은 최대 흡기 위치에 다소 흐림 허상이 나타나는 것을 볼 수 있었다. E패턴은 호흡이 일정하게 유지되는 구간은 없으나 흡기 구간에서 완만한 구간은 표적이 상대적으로 느리게 움직이므로 $\mathrm{D}$ 패턴에 비해 표적이 길게 나타난다. $\mathrm{B}$ 와 $\mathrm{C}$ 패 턴은 최대 흡기와 최대 호기 위치에 머무는 시간이 $\mathrm{A}$ 패턴 에 비해 짧지만 중앙에서 표적 이동 시간은 길다. 따라서 $\mathrm{A}$ 패턴에 비해 표적이 중앙에 더 잘 나타나는 것을 알 수 있다(Fig. 7).

Table 3은 호흡주기가 3 초이고, 표적의 진폭이 $3 \mathrm{~cm}$ 일 때 4DCT와 Slow-CT 영상에서 패턴에 따라 상, 하 방향에 대하여 표적의 재현성이 달라짐을 보여준다. $4 \mathrm{DCT}$ 와 Slow$\mathrm{CT}$ 간의 ITV 길이의 차이는 Table 2 에서 보는 바와 같이 호
흡주기 3 초, 진폭 $3 \mathrm{~cm}$ 의 경우 $\mathrm{A}$ 패턴의 경우 $16 \%, \mathrm{~B}, \mathrm{C}$, $\mathrm{E}$ 패턴에서 약 $18 \%, \mathrm{D}$ 패턴의 경우 $28 \%$ 를 보였다. 그러나 상, 하 방향으로 나누어서 그 차이를 비교해 보면 $\mathrm{A}, \mathrm{B}, \mathrm{C}$ 패턴의 경우 상, 하 방향에 대하여 $3 \mathrm{~mm}$ 이하의 차이를 보 인 반면 $\mathrm{E}$ 패턴은 상 방향이 하 방향에 비해 $5 \mathrm{~mm}$ 이상 차 이가 났다. 특히, D 패턴의 경우 상 방향은 차이가 없지만 하 방향의 경우 $1.45 \mathrm{~cm}$ 로 상, 하 방향에 대하여 전혀 다른 차이를 보였다. 그러므로 4DCT에 대하여 Slow-CT에 여유 를 정의할 때, 표적의 움직임을 고려하여 $\mathrm{A}, \mathrm{B}, \mathrm{C}$ 패턴에서 는 최대 흡기와 호기에 동일한 비율로 여유를 설정하고 $\mathrm{E}$ 패턴은 최대 흡기에 비해 호기에 2 배 정도 여유를 더 고려 해야 하며 $\mathrm{D}$ 패턴은 최대 흡기에만 여유를 설정해도 될 것 으로 판단된다.

본 연구는 4DCT와 Slow-CT 영상에 나타난 표적의 윤곽 을 묘사하여 ITV 길이와 체적을 평가함에 있어 몇몇의 한

Table 2. The difference of ITV length and ITV between Slow-CT and 4DCT according to respiratory patterns, respiratory period and target motion. The "( )" means the positive values and the other means that negative values.

\begin{tabular}{|c|c|c|c|c|c|c|c|c|c|}
\hline \multicolumn{2}{|c|}{$\mathrm{RP}$} & \multicolumn{2}{|c|}{$1 \mathrm{~s}$} & \multicolumn{2}{|c|}{$2 \mathrm{~s}$} & \multicolumn{2}{|c|}{$3 \mathrm{~s}$} & \multicolumn{2}{|c|}{$4 \mathrm{~s}$} \\
\hline $\mathrm{TM}$ & Pattern & $\begin{array}{c}\text { Diff ITV } \\
\text { length }(\%)\end{array}$ & Diff ITV (\%) & $\begin{array}{c}\text { Diff ITV } \\
\text { length }(\%)\end{array}$ & Diff ITV (\%) & $\begin{array}{c}\text { Diff ITV } \\
\text { length }(\%)\end{array}$ & Diff ITV (\%) & $\begin{array}{c}\text { Diff ITV } \\
\text { length }(\%)\end{array}$ & Diff ITV (\%) \\
\hline \multirow[t]{5}{*}{$1 \mathrm{~cm}$} & $\mathrm{~A}$ & 0.83 & $(0.90)$ & 8.83 & 15.85 & 8.89 & 17.33 & 13.02 & 19.37 \\
\hline & $\mathrm{B}$ & 0.68 & 5.69 & 8.39 & 13.78 & 13.83 & 18.75 & 12.56 & 18.79 \\
\hline & $\mathrm{C}$ & 0.00 & $(0.67)$ & 8.48 & 11.79 & 12.06 & 17.59 & 10.73 & 19.16 \\
\hline & $\mathrm{D}$ & $(0.20)$ & 0.00 & 11.17 & 15.67 & 9.34 & 18.57 & 14.48 & 23.09 \\
\hline & $\mathrm{E}$ & 0.21 & 2.66 & 3.45 & 11.80 & 4.91 & 16.96 & 10.36 & 19.21 \\
\hline \multirow[t]{5}{*}{$2 \mathrm{~cm}$} & $\mathrm{~A}$ & 0.79 & 0.79 & 10.90 & 19.61 & 14.38 & 24.91 & 12.84 & 26.37 \\
\hline & $\mathrm{B}$ & (2.03) & $(1.57)$ & 8.30 & 17.77 & 15.13 & 25.61 & 13.81 & 26.46 \\
\hline & $\mathrm{C}$ & 7.91 & 5.58 & 3.62 & 20.17 & 21.55 & 25.95 & 21.50 & 29.06 \\
\hline & $\mathrm{D}$ & $(7.92)$ & $(1.51)$ & 19.05 & 24.85 & 17.09 & 28.51 & 21.72 & 30.67 \\
\hline & $\mathrm{E}$ & 9.19 & 10.89 & 9.02 & 18.46 & 15.83 & 24.34 & 19.99 & 29.10 \\
\hline \multirow[t]{5}{*}{$3 \mathrm{~cm}$} & $\mathrm{~A}$ & 1.29 & 1.51 & 13.18 & 20.76 & 15.81 & 27.91 & 15.75 & 30.28 \\
\hline & $\mathrm{B}$ & 4.12 & 7.51 & 14.50 & 26.38 & 17.97 & 32.05 & 20.18 & 33.91 \\
\hline & C & 4.80 & 9.61 & 13.49 & 26.77 & 18.86 & 31.77 & 23.51 & 35.55 \\
\hline & $\mathrm{D}$ & 6.05 & 7.72 & 14.88 & 26.15 & 28.18 & 42.26 & 20.92 & 35.68 \\
\hline & $\mathrm{E}$ & 8.09 & 8.74 & 16.39 & 26.64 & 18.30 & 30.63 & 26.07 & 37.24 \\
\hline
\end{tabular}

RP: Respiratory periods, TM: Target motion.

Table 3. Measured Slow-CT different length for 4DCT at SI directions when respiratory period is 3 seconds and target motion is $3 \mathrm{~cm}$. In the table, the "S" means for superior direction and the "I" means for inferior direction.

\begin{tabular}{|c|c|c|c|c|c|c|c|c|c|c|}
\hline \multirow{2}{*}{$\begin{array}{c}\text { Pattern } \\
\text { Direction }\end{array}$} & \multicolumn{2}{|c|}{ A } & \multicolumn{2}{|c|}{ B } & \multicolumn{2}{|c|}{$\mathrm{C}$} & \multicolumn{2}{|c|}{$\mathrm{D}$} & \multicolumn{2}{|c|}{ E } \\
\hline & S & I & S & I & S & I & S & I & S & I \\
\hline Length $(\mathrm{cm})$ & -0.59 & -0.29 & -0.30 & -0.53 & -0.45 & -0.49 & 0.00 & -1.45 & -0.72 & -0.22 \\
\hline Error $(\mathrm{cm})$ & \pm 0.01 & \pm 0.01 & \pm 0.01 & \pm 0.01 & \pm 0.01 & \pm 0.05 & \pm 0.00 & \pm 0.07 & \pm 0.12 & \pm 0.01 \\
\hline
\end{tabular}


계가 있었다. 이는 절편 두께 및 윈도우 레벨/폭에 의한 것 이다. 즉, 본 연구에서는 영상을 촬영 시 절편 두께를 2.5 $\mathrm{mm}$ 로 하였으므로 절편 사이의 표적은 횡단면 영상에 표현 할 수가 없다. 이로 인해 이론적으로 최대 $4.8 \mathrm{~mm}$ 의 ITV 길이의 오차가 발생 할 수 있다. 이러한 이유로 미국의학물 리학회 보고서(AAPM TG-101)에서는 정위방사선치료 시, $\mathrm{CT}$ 의 절편 두께를 $3 \mathrm{~mm}$ 이하로 설정할 것을 권고하고 있 다. ${ }^{10)}$

윈도우 레벨 및 폭의 경우 본 연구에서는 $180 /-500$ 를 설 정하여 표적을 묘사하였는데 Fig. 8에서 보는 바와 같이 설 정을 변경하면 표적이 더 많이 표현됨을 알 수 있다. Dalah 등의 연구에서는 다양한 지름의 표적이 있는 팬톰을 촬영 하여 -191 과 -542 의 윈도우 레벨에서 표적의 지름을 측 정한 결과, 각 윈도우 레벨에서 나타난 지름 차이가 최대 2 $\mathrm{mm}$ 의 차이를 보임을 보고한 바 있다. ${ }^{11)}$

\section{결 론}

본 연구에서는 호흡 동조 구동 팬톰을 이용하여 호흡패 턴, 호흡주기 그리고 표적 진폭의 변화에 따른 4DCT와 Slow-CT 영상에서의 내부표적체적의 변화를 확인하기 위 해서 획득한 영상에 표적을 묘사하여 ITV 길이 및 체적에 대하여 비교, 분석하였다. 이론적인 ITV 체적과의 비교에 서 4DCT 영상이 Slow-CT 영상에 비해 표적을 잘 표현하였 지만 호흡주기, 진폭 그리고 호흡패턴에 따라 차이를 보임 을 확인하였다. 또한 4DCT와 Slow-CT 영상 비교한 결과, 호흡패턴에 따라 상, 하 방향의 차이가 달라짐을 보였다. 그러므로 Slow-CT 영상에 표적의 움직임을 고려한 여유를 설정할 때, 패턴별로 상, 하 방향에 다른 여유가 고려되어 야 한다고 판단된다. 향후 환자의 호흡 신호를 바탕으로 $\mathrm{CT}$ 영상을 분석할 때 본 연구에서 수행한 데이터가 유용 하게 사용될 수 있을 것으로 사료된다.

\section{References}

1. Heck B, Jess-Hempen A, Kreiner HJ, Schopgens $H$, Mack A: Accuracy and stability of positioning in radiosurgery: Long term results of the Gamma Knife system. J Appl Clin Med Phys 34:1487-1495 (2007)

2. Ryu SI, Chang SD, Kim DH, Murphy MJ, Le QT, Martin DP, et al: Image-guided hypo-fractionated stereotactic radiosurgery to spinal lesions. Neurosurgery 49(4):838-846 (2001)

3. Teh BS, Paulino AC, Lu HH, et al: Versatility of the Novalis System to deliver Image-Guided Stereotactic Body Radiation Therapy(SBRT) for Various Anatomical Sites. Technology in Cancer Research \& Treatment 6(4):347-354 (2007)

4. Keall PJ, Mageras GS, Balter JM, et al: The management of respiratory motion in radiation oncology: report of AAPM Task Group 76. (2006)

5. Keall PJ, Starkschall G, Shukla H, et al: Acquiring 4D thoracic CT scans using a multislice helical method. Phys Med Biol 49(10):2053-2067 (2004)

6. Lagerwaard F, John R, Van Sornsen De Koste, et al: Multiple "Slow" CT Scans for Incorporating Lung Tumor Mobility in Radiotherapy Planning. Int $\mathrm{J}$ Radiation Oncology Biol Phys 51(4):932-937 (2001)

7. 김수산, 하성환, 최은경, 이병용: 전산화단층촬영 주사시간 (Scan Time)이 폐종양운동의 재현성에 미치는 영향 분석. 대한 방사선종양학회지 22(1):55-63 (2004)

8. Nakamura M, Narita Y, Matsuo Y, et al: Geometrical differences in target volumes between Slow-CT and 4D CT imaging in stereotactic body radiotherapy for lung tumors in the upper and middle lobe. Med Phys 35(9):4142-4128 (2008)

9. Clements N, Kron T, Franich R, et al: The effect of irregular breathing patterns on internal target volumes in four-dimensional CT and cone-beam CT images in the context of stereotactic lung radiotherapy. Med Phys 40(2):021904;1-10 (2013)

10. Benedict SH, Yenice KM. Followill D, et al: Stereotactic body radiation therapy : The report of AAPM Task Group 101. Med Phys 37(8):4078-4101 (2010)

11. Dalah EZ, Nisbet A, Bradley D: Effect of window level on target volume delineation in treatment planning. Appl Radiat Isotopes p1-3 (2009) 


\section{호흡 동조 구동 팬톰을 이용한 호흡패턴에 따른 4DCT, Slow-CT의 내부표적체적 변화 연구}

*과학기술연합대학원대학교 원자력암의학, ${ }^{\dagger}$ 한국원자력의학원 방사선치료연구부,

${ }^{\ddagger}$ 한국원자력의학원 방사선종양학과, ${ }^{\S}$ 한양대학교 원자력공학과, "순천향대학교 천안병원 방사선종양학과

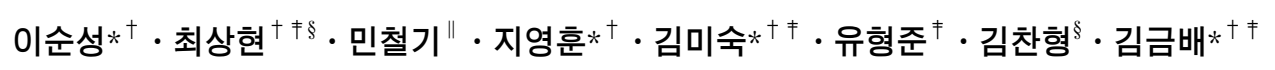

본 연구에서는 호흡 동조 구동 팬톰을 이용하여 5가지의 호흡패턴에 따른 4DCT와 Slow-CT의 내부표적체적(ITV) 변화를 비교 분석하였다. 각 호흡패턴마다 호흡주기 1 4초와 표적 진폭 1 3 cm를 적용하여 4DCT와 Slow-CT를 각 3회 촬영 하였다. 촬영한 영상들은 Eclipse 치료계획 시스템으로 표적을 윤곽 묘사하고 내부표적체적(ITV) 길이와 체적을 측정하였 으며, $4 \mathrm{DCT}$, Slow-CT의 ITV 길이와 체적의 평균값을 이론값과 비교하여 분석하였다. 4DCT에서의 ITV 길이와 체적은 호 흡주기가 길수록, 표적 진폭이 짧을수록 이론값과의 차이가 감소하는 경향을 보였다. Slow-CT에서는 표적 진폭이 커질 수록 4DCT와 마찬가지로 이론값과의 차이가 커졌으나 호흡주기에 따른 ITV 길이와 체적의 변화는 호흡주기 1 초에서 가 장 이론값 비슷하였고 2 4초 내에서는 재현성의 변화가 근소했다. 호흡패턴에 따라서는 4DCT, Slow-CT 모두 ITV 길이 와 체적에 대해 $\mathrm{A}$ 패턴에서 가장 높은 재현성을 보였고, $\mathrm{B}, \mathrm{C}, \mathrm{D}$ 패턴은 서로 비슷한 차이를 보였으며 $\mathrm{E}$ 패턴은 다른 네 패턴에 비해 이론값과의 차이가 가장 컸다. 4DCT에 대한 Slow-CT의 ITV 길이와 체적의 차이는 모든 호흡패턴에 대하여 호흡주기가 길수록, 표적 진폭이 클수록 증가하였다. 4DCT와 Slow-CT 영상간의 ITV 길이 및 체적에 대한 재현성을 비교 했을 때 Slow-CT가 4DCT에 비해 평균적으로 약 $22 \%$ 낮았으며, 호흡패턴에 따라 상, 하 방향에 대해 표적의 재현성이 달라졌다. $\mathrm{A}, \mathrm{B}, \mathrm{C}$ 패턴의 경우 상, 하 방향으로 $3 \mathrm{~mm}$, E패턴은 상 방향에 비해 하 뱡향에서 $5 \mathrm{~mm}$ 의 차이를 보인 반면에 $\mathrm{D}$ 패턴에서는 상 방향으로는 차이가 없었으나 하 방향으로 $1.45 \mathrm{~cm}$ 의 차이가 났다. 따라서 $4 \mathrm{DCT}$ 에 대하여 Slow-CT에 표적 움직임을 고려한 여유를 설정할 경우에는 호흡패턴에 따라 상, 하 방향에 다른 여유를 정의해야 한다고 판단된다. 향후 환자의 호흡신호를 바탕으로 CT 영상을 분석할 때 본 연구에서 수행한 데이터가 유용하게 사용될 것으로 사료된 다.

중심단어: $4 \mathrm{DCT}$, Slow-CT, 호흡패턴, 호흡동조구동팬톰, 내부표적체적 